\begin{tabular}{|c|c|}
\hline Title & Two-Layer Formation of Passivating Films on Cobalt in Neutral Solution \\
\hline Author(s) & Ohtsuka, Toshiaki; Sato, Norio \\
\hline Citation & $\begin{array}{l}\text { J. Electrochemical Society, 128(12), 2522-2528 } \\
\text { https://doi.org/10.1149/1.2127284 }\end{array}$ \\
\hline Issue Date & $1981-12$ \\
\hline Doc URL & http:/hdl.handle.net/2115/62202 \\
\hline Rights & $\begin{array}{l}\text { () The Electrochemical Society, Inc. 1981. All rights reserved. Except as provided under U.S. copyright law, this work } \\
\text { may not be reproduced, resold, distributed, or modified without the express permission of The Electrochemical Society } \\
\text { (ECS). The archival version of this work was published in J. Electrochem. Soc. } 1981 \text { volume 128, issue 12, 2522-2528. }\end{array}$ \\
\hline Tyре & article \\
\hline File Information & J.Electrochem.Soc.128,2522-2528(1981), T wo-lay er formation of --- cobalt.pdf \\
\hline
\end{tabular}

Instructions for use 


\title{
Two-Layer Formation of Passivating Films on Cobalt in Neutral Solution
}

\author{
Toshiaki Ohtsuka and Norio Sato* \\ Electrochemistry Laboratory, Corrosion Research Group, \\ Faculty of Engineering, Hokkaido University, Sapporo 060, Japan
}

\begin{abstract}
Layer structure and thickness of passivation oxide films on cobalt have been investigated at stationary and transient states in solution of $0.30 \mathrm{~mol}$ $\mathrm{dm}^{-3}$ boric acid $-0.075 \mathrm{~mol} \mathrm{dm}-3$ sodium borate mixture of $\mathrm{pH} 8.4$ by means of chemical analysis and in situ ellipsometry combined with electrochemical measurements. A two-layer structure composed of an inner $\mathrm{CoO}$ and an outer $\mathrm{Co}_{3}-\Delta \mathrm{O}_{4}$ is found in a potential range more positive than $0.75 \mathrm{~V}$ (vs. the hydrogen electrode at the same solution). The nonstoichiometry changes from $\Delta=0$ to 0.33 with increasing anodic potential. The outer $\mathrm{Co}_{3}-\mathrm{O}_{4}$ layer thickness increases linearly with potential, whereas the inner layer thickness is not a simple function of potential, but depends on the film formation procedure. A step-wise potential increase gives an initial rapid growth of the outer $\mathrm{Co}_{3-\Delta} \mathrm{O}_{4}$ layer followed by a gradual thickening of the inner CoO layer. The transient film growth behavior is interpreted in terms of a field-assisted ion diffusion mechanism, and the self-diffusion coefficient in the inner $\mathrm{CoO}$ layer is estimated to be $D / \mathrm{cm} \mathrm{sec}^{-1}=6.5 \times 10^{-21} \sim 2.6 \times$ $10-20$.
\end{abstract}

The previous papers (1-4) have shown that the passive oxide film on cobalt is potential dependent in neutral boric acid-sodium borate solution of $\mathrm{pH} 8.4$. At potentials more negative than $0.86 \mathrm{~V}$, referred to the hydrogen electrode in the same solution (HESS), a slightly soluble oxide film of $\mathrm{CoO} 2 \sim 3 \mathrm{~nm}$ thick is formed under stationary potentiostatic conditions (2-3). At more positive potentials a two-layered film is formed, consisting of an inner $\mathrm{CoO}$ and an outer $\mathrm{Co}_{3}-\mathrm{O}_{4}$ layer (2-3). The nonstoichiometry $\Delta$ of the outer layer depends on the anodic potential, changing from $\Delta=0$ at $1.15 \mathrm{~V}$ to $\Delta=0.33$ at $1.4 \mathrm{~V}$. The outer layer thickness increases linearly with the potential, whereas the inner layer thickness is not a simple function of potential. In the present paper the kinetics and mechanism of electrochemical formation of twolayered oxide films on cobalt were studied by using a potential step technique associated with the ellipsometric measurements.

\section{Experimental}

The specimens were prepared from cobalt rods of 99.99\% purity (Johnson-Matthey Limited) into polycrystalline sheets $0.8 \mathrm{~mm}$ thick with the surface area of 5 or $10 \mathrm{~cm}^{2}$. The specimen pretreatment was the same as that described in the previous papers (1-4). The electrolytes were prepared from doubly distilled water and analytical grade reagents. Anodic formation of the passive films on cobalt was performed in a mixture of $0.30 \mathrm{~mol} \mathrm{dm}^{-3}$ boric acid and 0.075 mol dm $\mathrm{dm}^{-3}$ sodium borate solutions at $p H$ 8.4. Cathodic reduction of the passive films was conducted in a mixture of boric acid and sodium borate solutions at $p H$ 6.5. A boric acid solution at $p H 5.3$ and a mixture of $0.5 \mathrm{~mol} \mathrm{dm}^{-3} \mathrm{NH}_{4} \mathrm{Cl}$ and $0.5 \mathrm{~mol} \mathrm{dm}^{-3} \mathrm{NH}_{4} \mathrm{OH}$ at $\mathrm{pH} 9.6$ were also used for spontaneous dissolution of the passive films. Furthermore, a solution of boric acid-sodium borate mixture at $p H \quad 8.4$ containing Co(II) ions at concentration of $1.03 \mathrm{mg} \mathrm{dm}-3$ was used for anodic deposition of a Co(III) oxide film from $\mathrm{Co}$ (II) ions on a $\mathrm{Pt}$ electrode with the surface area of $10 \mathrm{~cm}^{2}$. All the solutions were deaerated by bubbling purified nitrogen gas for more than $24 \mathrm{hr}$.

*lectrochemical Society Active Member. Key words: metals, anode, ellipsometry, passivity.
The ellipsometer used was of horizontal type with a quarter-wave plate placed on the side of incident beam. The fast axis of the plate was fixed at a $45^{\circ}$ orientation. Measurements were made by the standard null method at a wavelength of $\lambda / \mathrm{nm}=546$ and at an incidence angle of $\Phi_{1}=73.303^{\circ}(3,5)$.

All measurements were made at $20.0^{\circ} \pm 0.2^{\circ} \mathrm{C}$. The potential of cobalt electrodes was measured in reference to a saturated calomel electrode (SCE) and converted to a scale of the hydrogen electrode in the same solution (HESS).

The amount of cobalt ion dissolved into solutions was analyzed by a colorimetric nitroso-R-salt method.

\section{Result}

Two-layer structure of passivation films.-Figure 1 illustrates the results of ellipsometric measurements (Fig. 1a), the amount of dissolved Co(II) ion from the passive film, $W_{\mathrm{d}}$, and the decay of potential, $\Phi$, (Fig. 1b) during a galvanostatic cathodic reduction of a passive film on cobalt. The passive film was formed by $1 \mathrm{hr}$ oxidation at a constant potential in the solution of $p H 8.4$ and the reduction was performed at a constant current in the solution of $p H$ 6.5. The loci of polarizer azimuth $P$ and analyzer azimuth $A$ are directly plotted in Fig. 1a, where $P_{0}$ and $A_{0}$ correspond to the oxide-free reference surface of cobalt; $P_{\mathrm{o}}=$ $28.68^{\circ}$ and $A_{0}=4.43^{\circ}$ determine the complex refractive index of metallic cobalt, $\hat{\mathrm{n}}_{\mathrm{Co}}=2.83-3.86 \mathrm{i} \quad(2,3)$. The loci $\delta P$ vs. $\delta A$ exhibit two breaks at the points marked on $Q_{c}{ }^{\circ}$ and $Q_{c}{ }^{M}$, which appear to correspond to two breaks observed in $W_{\mathrm{d}}$ vs. $Q_{\mathrm{c}}$ and $\Phi$ vs. $Q_{\mathrm{c}}$ curves. In view of the previous results $(3,4)$, it is found that $Q_{c}{ }^{0}$ is the cathodic charge required for the nonstoichiometry $\Delta$ of the outer $\mathrm{Co}_{3-\Delta} \mathrm{O}_{4}$ layer to decreases to $\Delta=0$, and that $Q_{\mathrm{c}} \mathrm{M}$ is the charge required for the outer layer to be completely reduced to $\mathrm{Co}^{2+}$ ions. Thus, the reaction for $Q_{c}{ }^{0}$ and the reaction for $Q_{c}{ }^{M}-Q_{c}{ }^{\circ}$ are respectively represented by reactions [A] and [B]

$$
\begin{aligned}
\mathrm{Co}_{3-\Delta} \mathrm{O}_{4}+\frac{8 \Delta}{3} \mathrm{H}^{+} & +\frac{8 \Delta}{3} e \\
& \rightarrow\left(1-\frac{\Delta}{3}\right) \mathrm{Co}_{3} \mathrm{O}_{4}+\frac{4 \Delta}{3} \mathrm{H}_{2} \mathrm{O}
\end{aligned}
$$



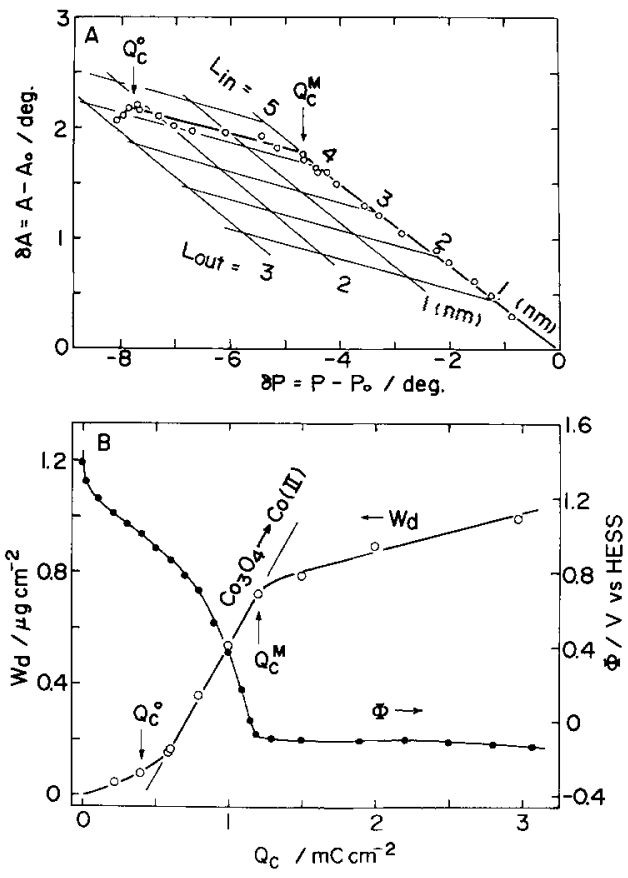

Fig. I. Cathodic reduction of a passive film at constant C.D. $i_{\mathrm{c}}=5 \mu \mathrm{A} \mathrm{cm}-2$ in borate solution of $p H$ 6.5. The film was formed ot constant potential, $\Phi=1.34 \mathrm{~V}$, for $1 \mathrm{hr}$ in borate solution of $\mathrm{pH}$ 8.4. (a) Change of ellipsometric parameters $P$ and $A$ during the reduction. (b) Amount of dissolved $C_{0}$ (II) from the film $W_{\mathrm{d}}$ and potential decay $\Phi$ as a function of cathodic charge $Q_{c}$ passed during the reduction.

$$
\mathrm{Co}_{3} \mathrm{O}_{4}+8 \mathrm{H}^{+}+2 e \rightarrow \mathrm{Co}^{2+}+4 \mathrm{H}_{2} \mathrm{O}
$$

The third stage of film reduction after $Q_{c}{ }^{M}$ is the reduction of the inner $\mathrm{CoO}$ layer.

To determine the complex refractive indexes of the layers, the best fit approach was made between the theoretical $\delta A$ vs. $\delta P$ loci for different complex refractive indexes and the experimental ones by taking into account the approximate film thickness estimated from the film charge in anodic oxidation and in cathodic reduction. The complex refractive indexes thus determined for the outer layer are $\hat{n}_{\mathrm{Co}_{2} \mathrm{O}_{3}}=3.2-0.95 \mathrm{i}$ and $\hat{n}_{\mathrm{Co}_{3} \mathrm{O}_{4}}=3.2-0.5 \mathrm{i}$, and for the inner layer $\hat{n}_{\mathrm{CoO}}=$ 2.3-0.1i $(2,3)$. In Fig. 1 the theoretical lines are also drawn for various thicknesses of the outer and the inner layers.

Figure 2 shows the $\delta A$ vs. $\delta P$ loci during the spontaneous dissolution of the passive film in two different solutions of $0.5 \mathrm{~mol} \mathrm{dm}^{-3} \mathrm{NH}_{4} \mathrm{OH}-0.5 \mathrm{~mol} \mathrm{dm}-3$ $\mathrm{NH}_{4} \mathrm{Cl}$ mixture at $p \mathrm{H} 9.6$ and of $0.30 \mathrm{~mol} \mathrm{dm}^{-3}$ boric acid at $p H$ 5.3, where no composition change of the film appears to occur during the dissolution because of the absence of applied cathodic current. The $\delta A v s$. $\delta P$ curves in Fig. 1 and 2 are almost the same.

Transient behavior.-To elucidate the layer growth, ellipsometric transient measurements of the film were carried out in two-step oxidation, in which, after renewal of the solution containing no dissolved cobalt ion, a potential step was applied to a preoxidized cobalt electrode. Figure 3 shows a $\delta A-\delta P$ curve observed after a potential step from 1.04 to $1.24 \mathrm{~V}$ is applied to a passivated cobalt that has been oxidized at $\Phi=$ $1.04 \mathrm{~V}(\mathrm{~V})$ for $1 \mathrm{hr}$. The filled circle in Fig. 3 indicates the values of $\delta P$ and $\delta A$ observed after cirect $1 \mathrm{hr}$ oxidation at $1.24 \mathrm{~V}$ starting from the oxide-free cobalt surface. It is noted that more than $6 \mathrm{hr}$ of oxidation is required for the $\delta P-\delta A$ value of two-step oxidation to reach that of direct one-step oxidation for $1 \mathrm{hr}$.

By superimposing on the results of Fig. 3 the theoretical $\delta P-\delta A$ loci calculated for two-layered films
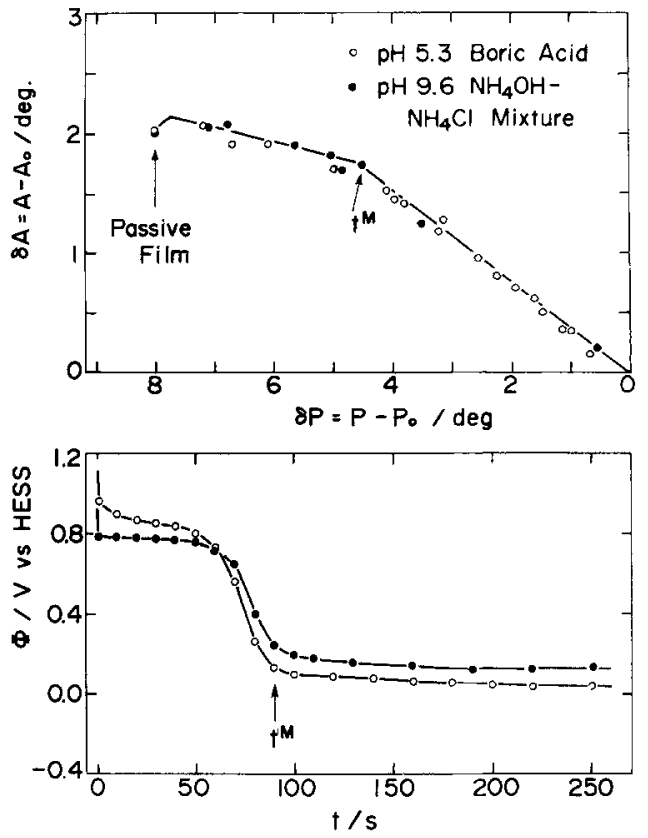

Fig. 2. Change of ellipsometric parameters $P$ and $A$ and potential decay during spontaneous dissolution of a passivation film in solutions of $0.5 \mathrm{~mol} \mathrm{dm}^{-3} \mathrm{NH}_{4} \mathrm{OH}-0.5 \mathrm{~mol} \mathrm{dm}^{-3} \mathrm{NH}_{4} \mathrm{Cl}$ mixture $(\triangle)$ and of $0.3 \mathrm{~mol} \mathrm{dm}^{-3}$ boric acid $(O)$. The break marked by $t^{M}$ in the $\delta P-\delta A$ loci corresponds to a point where the potential decays from the first to the second wave.

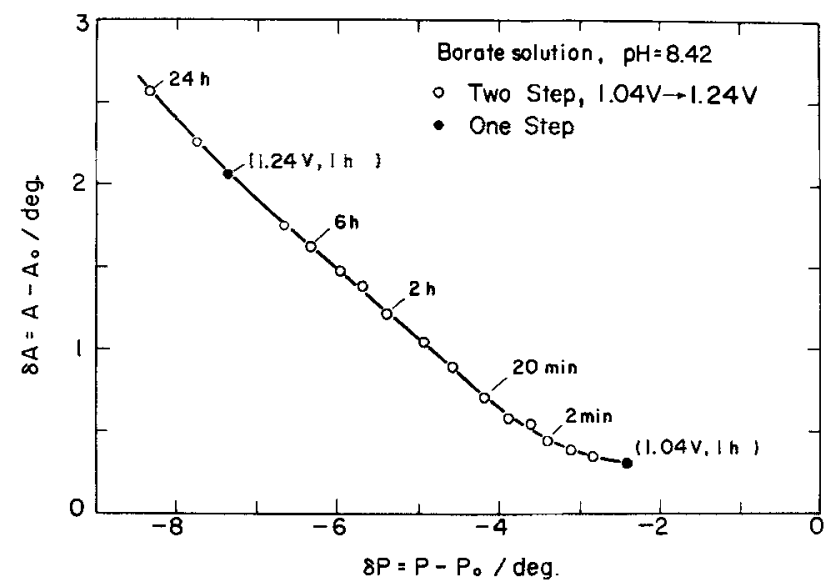

Fig. 3. Change in $\delta A$ vs. $\delta P$ loci with time during the second step at $\Phi=1.24 \mathrm{~V}$ in two-step oxidation in borate solution of $\mathrm{pH}$ 8.4. The electrode was first oxidized at $\Phi=1.04 \mathrm{~V}$ for $1 \mathrm{hr}$ (1st step) and after renewal of the solution was oxidized further at $\Phi=1.24 \mathrm{~V}$ (2nd step).

with the complex refractive indexes, $\hat{n}_{\text {CoO }}=2.3-0.1 i$ and $\hat{n}_{\mathrm{Co}_{3} \mathrm{O}_{4}}=3.2-0.5 \mathrm{i}$, as a function of layer thickness, the thickness of the both layers can be evaluated as a function of time during oxidation. In Fig. 4 and 5 the thickness change thus estimated is plotted together with the current density (C.D.) change. In Fig. 4 the thickness for $1.54 \mathrm{~V}$ oxidation at which gaseous oxygen evolves on the electrode was estimated using the complex refractive index of $\hat{n}_{\text {out }}=3.2-0.95 \mathrm{i}$ for the outer $\mathrm{Co}_{2} \mathrm{O}_{3}$ layer. It is seen that initially the outer layer increases accompanying no appreciable growth of the inner layer and that the inner layer begins to thicken after the outer layer grows to a certain thickness comparable to the thickness formed by direct one-step oxidation. It is noted that the inner layer formed by two-step oxidation is thinner than that formed by direct one-step oxidation. This is due to the anodic deposition of a Co(III) film from $\mathrm{Co}$ (II) 


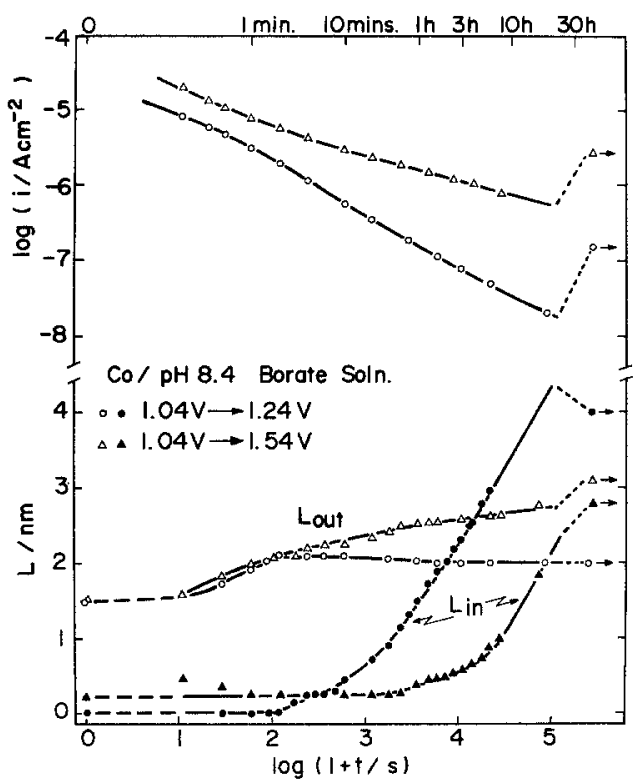

Fig. 4. Anodic C.D. $i$ and thicknesses of two layers $L_{\text {in }}$ and $L_{\text {out }}$ as a function of time during the second step at $\Phi=1.24 \mathrm{~V}$ and $1.54 \mathrm{~V}$ in two-step oxidation in borate solution of $\mathrm{pH}$ 8.4. The electrode was first oxidized ot $\Phi=1.04 \mathrm{~V}$ for $1 \mathrm{hr}$. The arrows on the right side indicate C.D.'s and thicknesses in direct one-step oxidation for $1 \mathrm{hr}$.

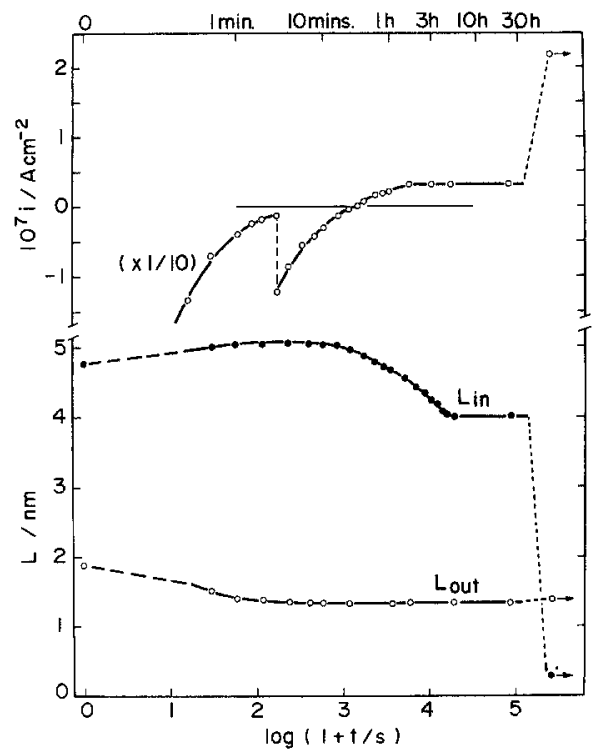

Fig. 5. Anodic C.D. and thicknesses of the two layers as a function of time during the second step at $\Phi=1.04 \mathrm{~V}$ in two-step oxidation in borate solution of $\mathrm{pH}$ 8.4. The electrode was first oxidized at $\Phi=1.24 \mathrm{~V}$ for $1 \mathrm{hr}$. The arrows on the right side indicate C.D. and thicknesses in direct one-step oxidation.

ions in aqueous solution produced prior to the film formation, as is shown later.

When the potential is stepped down (Fig. 5), an initial cathodic current causes a decrease of the outer layer thickness, producing a slight increase of the inner layer thickness, and then a definite decrease of the inner layer thickness occurs toward a steadystate value of $4.0 \mathrm{mn}$ without yielding any change in the outer layer thickness after the C.D. turns to be anodic.

The preferential growth of the outer layer, which occurs in an initial period of potential step oxidation (Fig. 4), also takes place during galvanostatic oxidation, as shown in Fig. 6. In this case the anodic C.D. of $1 \mu \mathrm{A} \mathrm{cm}-2$ was applied to a passivated cobalt electrode that has been oxidized at $1.03 \mathrm{~V}$ for $1 \mathrm{hr}$. Before

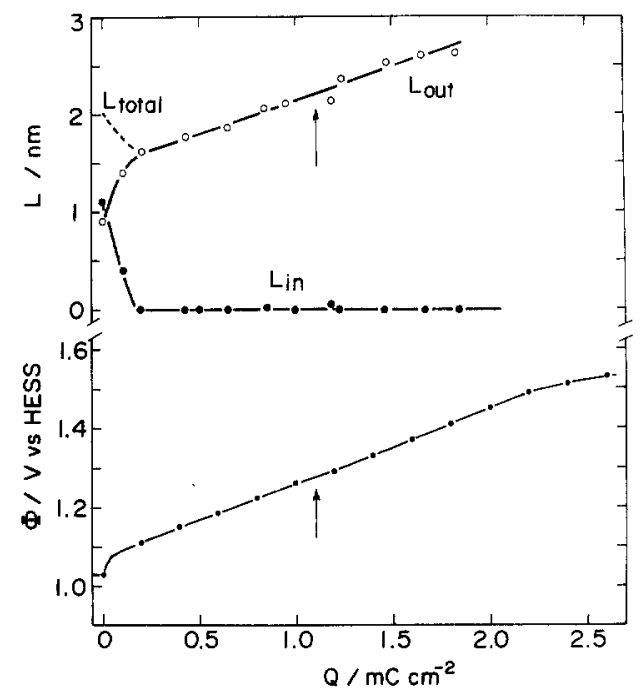

Fig. 6. Change in thickness and potential during galvanostatic oxidation at $i=1 \mu \mathrm{A}-\mathrm{cm}^{-2}$ of a film-covered cobalt electrode ( $L_{\text {in }}=1.1 \mathrm{~nm}$ and $L_{\text {out }}=0.9 \mathrm{~nm}$ ) which has been oxidized ot $\Phi=1.03 \mathrm{~V}$ in borate solution of $\mathrm{pH}$ 8.4. The arrow in the figure indicates the amount of charge passed at which the complex refractive index of $\mathrm{Co}_{3-\Delta} \mathrm{O}_{4}$ layer begins to change.

the galvanostatic oxidation, the film has consisted of the inner layer of $1.1 \mathrm{~nm}$ and the outer layer of 0.9 $\mathrm{nm}$. Application of a small anodic current first causes a rapid increase of the outer layer with a decrease of the inner layer and then the film of a single $\mathrm{Co}_{3} \mathrm{O}_{4}$ layer $(\hat{n}=3.2-0.5 i)$ with a linear rise of potential. Finally, the film transforms to $\mathrm{Co}_{2} \mathrm{O}_{3}(\hat{\mathrm{n}}=3.2-0.95 \mathrm{i})$ without producing any increase of the inner layer.

In Fig. 7 the change in the $\delta A$ vs. $\delta P$ loci is illustrated for the second step of oxidation at different potentials in the range of two-layer formation, starting from a passivated cobalt electrode that has been oxidized at $1.04 \mathrm{~V}$ for $1 \mathrm{hr}$. The $\delta P-\delta A$ value corresponding to the film formed by direct one-step oxidation for $1 \mathrm{hr}$ lies on the extrapolated growth line of two-step oxidation. At potentials more positive than $1.34 \mathrm{~V}$ the locus of the second step oxidation even after $22 \mathrm{hr}$ ( ) does not reach the value of the passivated electrode directly oxidized in one step for 1 $\mathrm{hr}(\mathrm{O})$. The second step oxidation at $1.54 \mathrm{~V}$ gives rise to transformation of $\mathrm{Co}_{3} \mathrm{O}_{4}$ to $\mathrm{Co}_{2} \mathrm{O}_{3}$ in an initial

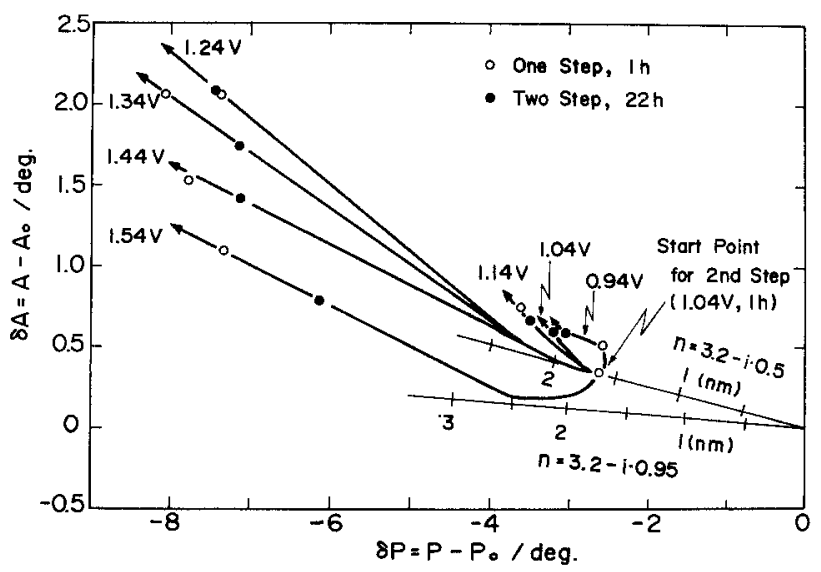

Fig. 7. Change in $\delta A$ vs. $\delta P$ loci during the second step at different potentials in two-step oxidation in borate solution of $\mathrm{pH}$ 8.4. The electrode was first oxidized at $\Phi=1.04 \mathrm{~V}$ for $1 \mathrm{hr}$. The filled circles indicate the values of $\delta P$ and $\delta A$ after $22 \mathrm{hr}$ of the second step in two-step oxidation and the open circles the values after $\mathbf{l ~ h r}$ in direct oxidation. 
period, as suggested by a change in the complex refractive index from $\hat{n}=3.2-0.5 i$ to $3.2-0.95 i$.

Comparisons of the thickness and the final C.D. are made in Fig. 8 between direct $1 \mathrm{hr}$ oxidation and twostep $22 \mathrm{hr}$ oxidation. In this figure the thickness and the C.D. in the potential region where the film of a single $\mathrm{CoO}$ layer is formed is also plotted. In the potential region for a two-layer film formation the final anodic C.D. in two-step oxidation is one-tenth times as small as that in direct one-step oxidation. Difference in C.D. between the potential regions of $\mathrm{Co}_{3} \mathrm{O}_{4}$ and $\mathrm{Co}_{2} \mathrm{O}_{3}$ formation can be seen in two-step oxidation, but becomes indistinct in direct one-step oxidation. The thickness of the outer layer does not depend on whether the film is formed by one-step or two-step oxidation and increases nearly linearly with potential except for the film formed above $1.4 \mathrm{~V}$. The inner layer thickness, however, differs in different oxidation procedures. It appears that the inner layer thickness of two-step oxidation is larger at potentials below $1.2 \mathrm{~V}$ and smaller at potentials above $1.3 \mathrm{~V}$ than that of direct one-step oxidation. From the above results it follows that the thickness of the outer layer is determined only by the oxidation potential, whereas the thickness of the inner layer is dependent on the oxidation procedure.

Anodic deposition of $\mathrm{Co}(I I)$ ion in solution.-The previous work (1) has shown that the amount of Co (II) ion dissolved in solution was $0.5 \mu \mathrm{g} \mathrm{cm}^{-2}$ in 5 sec oxidation and $0.03 \mu \mathrm{g} \mathrm{cm}-2$ in $1 \mathrm{hr}$ oxidation at constant potential $1.34 \mathrm{~V}$ starting from the film-free surface. This means that the Co(II) ion dissolved in solution in the initial period of anodic passivation is anodically deposited on the passivated cobalt. Another evidence on the anodic deposition is given from an experiment in which $\mathrm{Pt}$ electrode is potentiostatically oxidized for $1 \mathrm{hr}$ in the boric acid-sodium borate solution of $p \mathrm{H} 8.4$ containing $\mathrm{Co}_{\text {(II) }}$ ion of concentration $1.03 \mathrm{mg} \mathrm{dm}-3$. Figure 9 shows the amount of Co(II) ion anodically deposited from the solution to form a cobalt oxide film on $\mathrm{Pt}$, which was estimated from the decrease of $\mathrm{Co}_{\text {(II) }}$ ion concentration in the solution after potentiostatic $1 \mathrm{hr}$ oxidation at constant

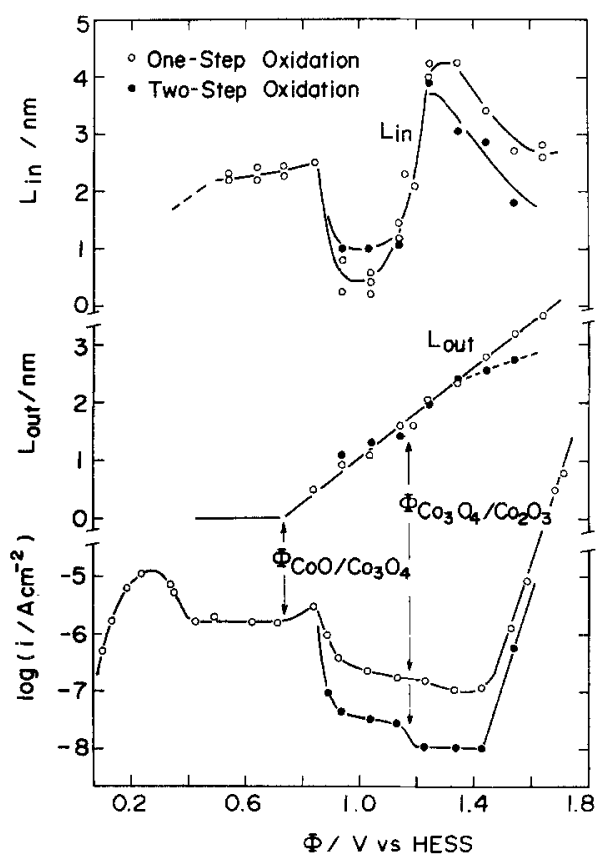

Fig. 8. Comparison of film thickness and anodic C.D. between one-step and two-step oxidations in borate solution of $\mathrm{pH}$ 8.4. The film thickness and anodic C.D. were measured ofter $1 \mathrm{hr}$ for onestep oxidation ond ofter $22 \mathrm{hr}$ for two-step oxidation.

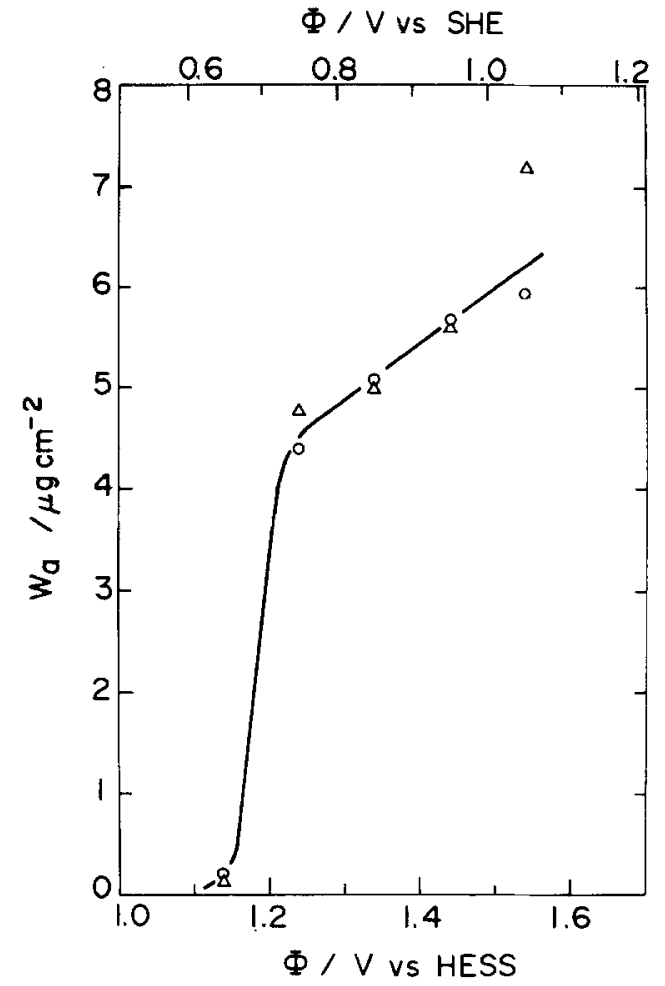

Fig. 9. Amount of cobalt ion anodically deposited on Pt electrode from borate solution containing $\mathrm{Co}_{(11)}$ ions. The amount of cobalt ion deposited was estimated from the decrease of $\mathrm{Co}_{0}(\mathrm{II})$ ion in solution during potentiostatic oxidation $(\Delta)$ and the cathodic $\mathrm{Co}_{0}$ (II) ion dissolution from the film into solution of $\mathrm{pH}$ 6.5 during subsequent galvanostatic reduction at $i=10 \mu \mathrm{A}-\mathrm{cm}^{-2}$ (O).

potential. The amount of $\mathrm{Co}$ (II) deposited was also evaluated from the amount of $\mathrm{Co}$ (II) ion dissolved from the film on $\mathrm{Pt}$ by galvanostatic reduction at 10 $\mu \mathrm{A} \mathrm{cm} \mathrm{cm}^{-2}$ in the boric acid-sodium borate solution of $p H$ 6.5. The anodic oxidation of Co(II) ion in the solution to form the film takes place at potentials more positive than $1.2 \mathrm{~V}$, which is in agreement with the potential at which an abrupt increase of the inner layer thickness as well as the outer layer nonstoichiometry $\Delta$ commences.

\section{Discussion}

Potential distribution in the passivation film.-We consider the two-layered structure of an inner $\mathrm{CoO}$ and an outer $\mathrm{Co}_{3}-\mathrm{O}_{4}$ shown in Fig. 10 and the potential distribution in the film shown in Fig. 11. If the reactions between the phases are in equilibrium at all the interphases, the irreversible potential differences in $\mathrm{CoO}$ (II phase) and in $\mathrm{Co}_{3}-\Delta \mathrm{O}_{4}$ (III phase) are given by

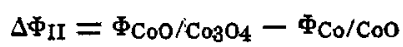

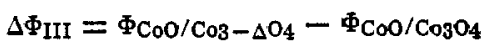

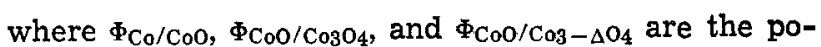
tentials of electrode systems consisting of $\mathrm{Co} / \mathrm{CoO}$, $\mathrm{Co} / \mathrm{CoO} / \mathrm{Co}_{3} \mathrm{O}_{4}$, and $\mathrm{Co} / \mathrm{CoO} / \mathrm{Co}_{3}-\Delta \mathrm{O}_{4}$, respectively. If we assume the potential of $\Phi_{\mathrm{Co} / \mathrm{CoO}}$ to be $0.14 \pm 0.04 \mathrm{~V}$ vs. HESS, thermodynamically estimated by Göhr (6), and the potential of $\Phi_{\mathrm{CoO} / \mathrm{Co} 3 \mathrm{O}_{4}}$ to be $0.75 \mathrm{~V}$, experimentally established by the authors $(\overline{1}, 4,7)$, the irreversible potential difference in the $\mathrm{COO}$ phase is

$$
\Delta \Phi_{\mathrm{II}} / \mathrm{V}=0.61 \pm 0.06
$$

It is this potential difference which creates the driving force for growth of the CoO layer. It follows from Eq. [2] that the irreversible potential difference in the outer $\mathrm{Co}_{3}-\mathrm{O}_{4}$ phase can not be defined as a con- 
stant value, but varies depending on the nonstoichiometry $\Delta$.

Thermodynamically, we can describe the outer layer composition as a function of electrode potential. The layer structure may also be thermodynamically described, but a number of kinetic parameters are required for the determination of the composition profile in depth.

A kinetic model for two-layer formation.-There have been only a few theoretical studies on the twolayer growth on metals. Yurek, Hirth, and Rapp (8) and Shaw and Rolls (9) have derived kinetic equations of two-layer growth for relatively thick oxide scales on metals. We propose here a kinetic mechanism of two-layer growth in anodic oxide films, which explains the observed transient behavior of anodic oxide film on cobalt. For simplification we assume that the diffusing ion through the film toward the solution is $\mathrm{Co}$ (II) ion and that the inner and the outer layers are $\mathrm{CoO}$ and $\mathrm{Co}_{3} \mathrm{O}_{4}$, respectively. Further, we assume the reaction scheme shown in Table I, where subscripts I, IIa, IIb, IIIa, IIIb, and IV indicate respectively the locations in the electrode system illustrated in Fig. 10. The reaction rate is expressed in terms of mol flux

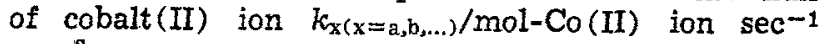
$\mathrm{cm}^{-2}$.

From the mass balance of transferring ions, the following relationship can be obtained among the reaction rates

and

$$
\begin{gathered}
k_{\mathrm{a}}=k_{\mathrm{b}} \\
k_{\mathrm{b}}=k_{\mathrm{c}}+k_{\mathrm{d}} \\
k_{\mathrm{c}}=k_{\mathrm{e}}
\end{gathered}
$$

$$
k_{\mathrm{e}}=k_{\mathrm{f}}+k_{\mathrm{g}}
$$

We now introduce the following quantities for the reaction rates

$$
\begin{gathered}
i_{\mathrm{II}} / \mathrm{A}-\mathrm{cm}^{-2}=2 F k_{\mathrm{b}} \\
i_{\mathrm{III}} / \mathrm{A}-\mathrm{cm}^{-2}=2 F k_{\mathrm{e}} \\
i_{\text {diss }} / \mathrm{A}-\mathrm{cm}^{-2}=2 F k_{f} \\
i_{\text {depos }} / \mathrm{A}-\mathrm{cm}^{-2}=2 F k_{\mathrm{h}}
\end{gathered}
$$

where $i_{I I}$ and $i_{\text {III }}$ correspond respectively to the ionic C.D. of diffusing $\mathrm{Co}$ (II) ion through the inner $\mathrm{CoO}$ and the outer $\mathrm{Co}_{3} \mathrm{O}_{4}$ layers, and $i_{\text {diss }}$ and $i_{\text {depos }}$ to the dissolution C.D. and the deposition C.D. These ionic C.D.'s can be used to describe the three experimentally measurable quantities, $i_{\mathrm{a}}, L_{\mathrm{in}}$, and $L_{\text {out }}$ by taking the mass balance given by Eq. [4], [5], [6], and [7] into account. From reactions $[\mathrm{a}],[\mathrm{b}],[\mathrm{g}]$, and $[\mathrm{h}]$, the anodic C.D. that can be measured is given by

$$
\begin{aligned}
i_{\mathrm{a}} & =\mathbf{F}\left(2 k_{\mathrm{a}}-2 k_{\mathrm{d}}+\frac{2}{3} k_{\mathrm{g}}+\frac{2}{3} k_{\mathrm{h}}\right) \\
& =\frac{4}{3} i_{\mathrm{III}}-\frac{1}{3} i_{\mathrm{diss}}+\frac{1}{3} i_{\text {depos }}
\end{aligned}
$$

Table I. Reaction scheme for growth of $\mathrm{CoO} / \mathrm{Co}_{3} \mathrm{O}_{4}$ two-layered film on $\mathrm{Co}_{0}$
Rate (mol-Co ion $\mathrm{sec}^{-1} \mathrm{~cm}^{-2}$ )

[a] $\mathrm{ICo} \rightarrow \mathrm{IIACo}^{2+}+2 \mathrm{I} e^{-}$

[b] $\mathrm{IIaCO}^{2+} \rightarrow \mathrm{IIbCO}^{2+}$

[c] $\mathrm{InCO}^{2+} \rightarrow \mathrm{IIIaCO}^{2+}$

[d] $\mathrm{IIbCo}^{2+}+\mathrm{III}_{\mathrm{C}} \mathrm{Co}_{4} \mathrm{O}_{4}+21 e \rightarrow 4 \mathrm{IIbCoO}$

[e] jua $\mathrm{Co}^{2+} \rightarrow$ IIIb $\mathrm{Co}^{2+}$

[f] $\mathrm{Irrb}^{2+} \rightarrow \mathrm{IrCO}^{2+}$

[g] $\mathrm{ImbCo}_{2}^{2+}+4 / 3 \mathrm{IV} \mathrm{H} \mathrm{H}_{2} \mathrm{O} \rightarrow 1 / 3 \mathrm{mIb} \mathrm{COsO}_{4}+8 / 3 \mathrm{IV} \mathrm{H}+$
$+2 / 3 \mathrm{re}$

[h] $\mathrm{rICo}^{2+}+4 / 3 \mathrm{w} \mathrm{H}_{2} \mathrm{O} \rightarrow 1 / 3 \mathrm{rinb} \mathrm{Co}_{3} \mathrm{O}_{4}+8 / 3 \mathrm{rv} \mathrm{H}+$

$+2 / 3$ I $e$

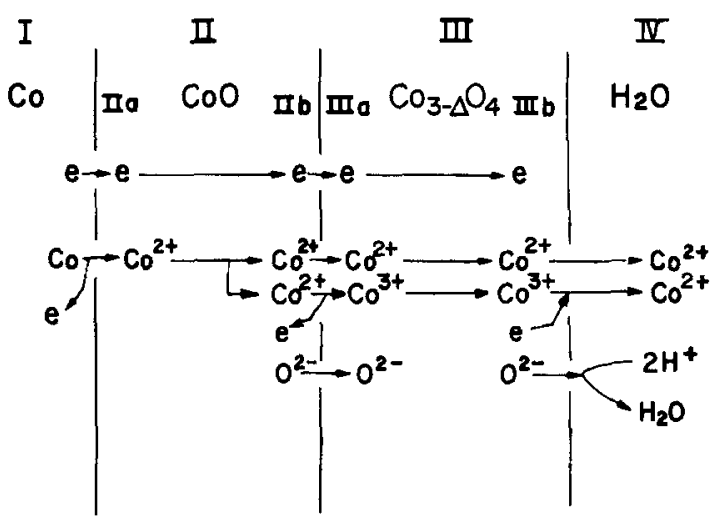

Fig. 10. Illustration of phase arrangement and reactions in twolayered passive films on cobalt.

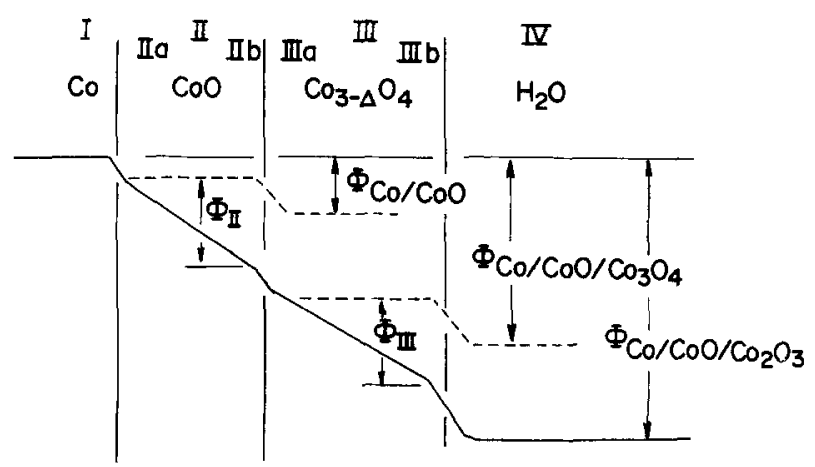

Fig. 11. A model of potential distribution in the two-loyered passive film on cobalt. Dotted lines indicate the possible potential distribution at equilibrium for $\mathrm{Co}_{0} / \mathrm{CoO}$ and $\mathrm{Co} / \mathrm{CoO} / \mathrm{CO}_{0} \mathrm{O}_{4}$ electrodes.

Since the inner layer increases in thickness by reaction $[d]$, the growth rate can be described from Eq. [6] and [7] in terms of $i_{\mathrm{II}}$ and $i_{\mathrm{III}}$

$$
\begin{aligned}
\frac{d L_{\text {in }}}{d t} & =8 \mathbf{F} k_{\mathrm{d}} \tilde{L}_{\mathrm{CoO}} \\
& =4\left(i_{\mathrm{II}}-i_{\mathrm{III}}\right) \tilde{L}_{\mathrm{COO}}
\end{aligned}
$$

where $\tilde{L}_{\mathrm{CoO}} / \mathrm{nm} \mathrm{cm} \mathrm{cm}^{-1}$ is the thickness of $\mathrm{CoO}$ equivalent to $1 \mathrm{C} \mathrm{cm}^{-2}$ of $\mathrm{Co}$ (II) ion. The outer layer grows by reactions [g] and [h], and its thickness decreases by reaction $[\mathrm{d}]$

$$
\begin{aligned}
\frac{d L_{\text {out }}}{d t} & =2 \mathbf{F}\left(k_{\mathrm{g}}+k_{\mathrm{h}}-3 k_{\mathrm{d}}\right) \tilde{L}_{\mathrm{Co3} 34} \\
& =\left\{i_{\mathrm{III}}-i_{\text {diss }}+i_{\text {depos }}-3\left(i_{\mathrm{II}}-i_{\mathrm{III}}\right)\right\} \tilde{L}_{\mathrm{CO} 304}
\end{aligned}
$$

where $\tilde{L}_{\mathrm{Co}_{3} \mathrm{O}_{4}} / \mathrm{nm} \mathrm{cm}^{2} \mathrm{C}^{-1}$ is the thickness of $\mathrm{Co}_{3} \mathrm{O}_{4}$ equivalent to $1 \mathrm{C} \mathrm{cm}^{-2}$ of $\mathrm{Co}$ (II) ion. Values of $\widetilde{L}_{\mathrm{CaO}}$ and $\widetilde{L}_{\mathrm{Co}_{3} \mathrm{O}_{4}}$ were experimentally obtained; $\widetilde{L}_{\mathrm{CoO}} / \mathrm{nm} \mathrm{cm}{ }^{2}$ $\mathrm{C}^{-1}=9.1 \times 10^{2}$ and $\tilde{\mathrm{L}}_{\mathrm{Co}_{3} \mathrm{O}_{4}} / \mathrm{nm} \mathrm{cm}^{2} \mathrm{C}^{-1}=7.7 \times 10^{2}$ $(2,3)$. From Eq. [13] and [14] it is evident that the growth of one layer is strongly dependent on the ionic C.D. of the diffusing Co (II) ion in the other layer.

It is assumed that the ionic flux through the layer is a function of electric field strength $E=\Delta \Phi / L$ following the Cabrera-Mott theory $(10,11)$.

$$
\begin{gathered}
i_{\mathrm{II}}=i_{\mathrm{II}, 0} \exp \left(B_{\mathrm{II}} \Delta \Phi_{\mathrm{II}} / L_{\mathrm{in}}\right) \\
i_{\mathrm{III}}=i_{\mathrm{III}, 0} \exp \left(B_{\mathrm{III}} \Delta \Phi_{\mathrm{III}} / L_{\text {out }}\right)
\end{gathered}
$$

where $i_{I I, 0}$ and $i_{\text {III,0 }}$ indicate the ionic self-diffusion C.D. at zero field, and $B_{I I}$ and $B_{I I I}$ are constants given 
below

$$
\begin{gathered}
B_{\mathrm{II}}=Z_{\mathrm{II}} a_{\mathrm{II}} \mathrm{F} / R T \\
B_{\mathrm{III}}=Z_{\mathrm{III}} a_{\mathrm{III}} \mathrm{F} / R T
\end{gathered}
$$

in which $Z_{\mathrm{II}}$ or $Z_{\mathrm{III}}$ is the ionic valency of migrating ion, and $a_{\text {II }}$ or $a_{I I I}$ the jumping distance for ion migration.

Equations [12]-[16], which represent the increasing or decreasing thickness of the layers, can be used to understand qualitatively the observed transient behavior and may predict the thickness in some cases.

Film thickness at steady states.-At the stationary state, where $\left(d L_{\text {in }} / d t\right)=0,\left(d L_{\text {out }} / d t\right)=0$, and $\left(d i_{a} / d t\right)=0$, the ionic transfer across every interphase is equal to the ionic diffusion through every layer

$$
i_{\text {ss }}=i_{\text {II }}=i_{\text {III }}=i_{\text {diss }}
$$

where $i_{\text {ss }}$ represents the anodic C.D. at the stationary state. Correspondingly, the thicknesses are determined by Eq. [15] and [16]. As $\Delta \Phi_{1 I}$ remains equal to the irreversible potential difference given by Eq. [1] or [3] irrespective of the anodic potential, the thickness of the inner layer, $L_{\mathrm{in}}$, is determined by the dissolution rate, $i_{\text {diss, }}$ of the outer layer. It follows therefore that the inner layer, even if it is soluble, will grow to a certain thickness in the presence of the protective outer layer. Since the outer layer sustains an increasing potential difference $\Delta \Phi_{\text {III }}$ with anodic potential $\Delta \Phi_{\mathrm{T}}$, its thickness will increase with anodic potential at the stationary state

$$
\Delta \Phi_{I I I}=\Delta \Phi_{T}-\Delta \Phi_{I I}
$$

In our experimental results the thickness of the outer layer satisfies the above prediction for both onestep and two-step oxidation films, as shown in Fig. 8, whereas the thickness of the inner layer behaves differently depending on the formation procedure. It is thus suggested that the outer layer can approach the stationary thickness more quickly than the inner layer.

Anodic deposition of $\mathrm{Co}(I I)$ in solution.-The difference in the inner layer thickness between one-step oxidation film and two-step oxidation film is caused by the anodic deposition reaction [h] in Table $\mathrm{I}$, which occurs only in the one-step oxidation. As shown in Fig. 8 and 9, the potential at which the anodic deposition from $\mathrm{Co}$ (II) ion commences is in agreement with the potential at which an abrupt change of the inner layer thickness is observed. A question is now raised why the inner $\mathrm{CoO}$ layer does become thick, when Co(II) ions in the solution are deposited to form the outer layer of higher valence oxide. As the outer layer thickness increases by anodic deposition from Co ion, the rate of $\mathrm{Co}$ (II) ion diffusion in the outer layer decreases because of a decreasing electric field intensity in the layer according to Eq. [16] and eventually becomes negligible compared with the ionic diffusion rate in the inner layer

$$
i_{\mathrm{II}}>>i_{\mathrm{III}}=0
$$

From Eq. [13] therefore the inner layer growth rate is

$$
\frac{d L_{\mathrm{in}}}{d t}=4 i_{11} \tilde{L}_{\mathrm{CoO}}
$$

which means that almost all $\mathrm{Co}$ (II) ions flowing through the inner layer to the $\mathrm{CoO} / \mathrm{Co}_{3} \mathrm{O}_{4}$ interphase go into reaction [d] to form a new $\mathrm{CoO}$ layer at the expense of the outer $\mathrm{Co}_{3} \mathrm{O}_{4}$ layer. In this case the inner CoO layer may thicken without any diffusion of $\mathrm{Co}$ (II) ion through outer $\mathrm{Co}_{3-\Delta} \mathrm{O}_{4}$ layer which is a barrier against ion flow. By two-step oxidation, because of the absence of dissolved $\mathrm{Co}$ (II) ions in the solution, the film growth requires the diffusion of
Co(II) through both the layers and hence the film growth rate is small compared with that in one-step oxidation where the anodic deposition is involved.

Inner layer growth.-As shown in Fig. 4, when an anodic potential step was applied to a passivated cobalt, the outer layer was observed to grow first in an initial period of time until its thickness reached a steady value, where $d L_{\text {out }} / d t=0$. The initial growth of the outer layer was followed by a gradual increase of the inner layer thickness in the later period of time while the outer layer thickness remained constant. Therefore, for the later stage of film growth, we obtain by substituting $d L_{\text {out }} / d t=0$ and $i_{\text {depos }}=0$ into Eq. [13] and Eq. [14] the following equations

$$
\begin{gathered}
\left.\frac{d L_{\text {in }}}{d t}=i_{\mathrm{II}}-i_{\text {diss }}\right) \tilde{L}_{\mathrm{CoO}} \\
i_{\mathrm{a}}=i_{\mathrm{II}}
\end{gathered}
$$

Equation [23] means that the dissolution rate of the outer layer plays a large role in determining whether the inner layer increases or decreases after the outer layer reaches the stationary thickness. From Eq. [18] and the result shown in Fig. 4 and 5, it follows that the potential step from 1.04 to $1.24 \mathrm{~V}$ causes the inner layer to grow because $i_{\text {II }}>i_{\text {diss }}$ and that the reverse potential step brings about a decrease of the inner layer because $i_{\mathrm{II}}<i_{\text {diss }}$.

The growth rate of the inner layer can be described from the results of Fig. 4 and from Eq. [24] by assuming the Cabrera-Mott relation of Eq. [15]. Figure 12 shows the relationship between the logarithm of anodic C.D. $i_{\text {II }}$ and the inverse of the inner layer thickness during the second step oxidation at $1.24 \mathrm{~V}$ after the outer layer reaches the stationary thickness. From the slope and intersect of the curve, $B_{I I} \Delta \Phi_{I I} / \mathrm{cm}=4.3$ $\cdot 10^{-7}$ and $i_{\mathrm{II}, 0} / \mathrm{A}-\mathrm{cm}^{-2}=1.2 \cdot 10^{-8}$. If we assume $\Delta \Phi_{\mathrm{II}}=0.61(\mathrm{~V})$ from Eq. $[3], B_{\mathrm{T}} / \mathrm{cm} \mathrm{V} \mathrm{V}^{-1}=7.1 \times$ $10^{-7}$. From the value of $B_{\mathrm{II}}$ Eq. [17] gives $a_{\mathrm{II}} / \mathrm{cm}=1.8$ $\times 10^{-8}$ at $Z_{\mathrm{II}}=2$, and $a_{\mathrm{II}} / \mathrm{cm}=3.6 \times 10^{-8}$ at $Z=1$. By comparing the estimated $a_{\mathrm{II}}$ values with the distance between the neighboring $\mathrm{Co}$ ions in $\mathrm{CoO}$, calculated to be $0.30 \mathrm{~nm}$ from the lattice constant of $0.426 \mathrm{~nm}$, it is likely that the migrating species is monovalent cobalt vacancy. The ionic conductivity $\kappa$ at low fields may be written as

$$
\kappa=\left|\frac{\partial I_{I I}}{\partial\left(\Delta \Phi_{\mathrm{II}} / L_{\mathrm{in}}\right)}\right|_{\left(\Delta \Phi_{\mathrm{II}} / L_{\mathrm{in}}\right) \rightarrow 0}=i_{\mathrm{II}, 0} B_{\mathrm{II}}
$$

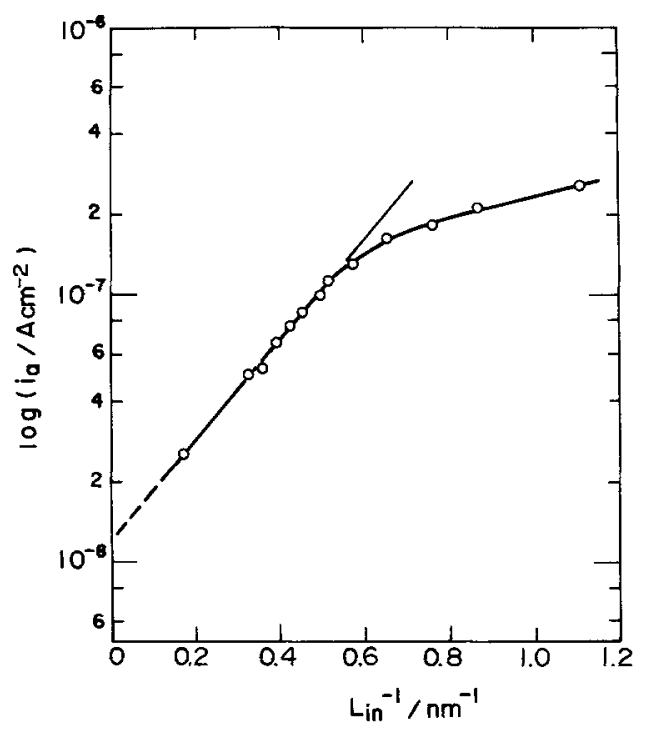

Fig. 12. Relation between inverse of the inner layer thickness and the anodic C.D. in logarithmic scale. Data correspond to the results of $\Phi=1,24 \mathrm{~V}$ oxidation in Fig. 4. 
and is estimated to be $\kappa / \mathrm{S} \mathrm{cm-1}=8.5 \times 10^{15}$. Furthermore, the self-diffusion constant $D$ of moving species in the inner layer may be estimated using EinsteinNerst relation (12), as follows

$$
D=\frac{i_{\mathrm{II}, 0} B_{\mathrm{II}} R T}{z^{2} \mathrm{~F}^{2}} \cdot \frac{1}{C_{\mathrm{Co}}}
$$

where $C_{\mathrm{Co}} / \mathrm{mol} \mathrm{cm} \mathrm{cm}^{-3}$ is the number of $\mathrm{mol}$ of $\mathrm{CoO}$ in unit volume and is calculated to be $C_{\mathrm{Co}} / \mathrm{mol} \mathrm{cm}-3=$ 0.086 from the lattice constant. We estimate that $D / \mathrm{cm}^{2}$ $\mathrm{sec}^{-1}=6.5 \times 10^{-21}$ for $Z=2$ and $D / \mathrm{cm}^{2} \mathrm{sec}^{-1}=2.6$ $\times 10^{-20}$ for $Z=1$. No comparable self-diffusion constant can be found in the literature and the estimated values in this work are $10^{10}$ times as large as the value extrapolated from the diffusion data for $\mathrm{CoO}$ obtained at high temperature above $1200 \mathrm{~K}$ by Richardson et al. (13) and by Chen et al. (14). The discrepancy may be attributed to a large concentration of lattice defects in the anodic oxide film.

\section{Conclusion}

The following conclusions may be drawn;

1. Cobalt is covered with a two-layered oxide film consisting of an inner $\mathrm{C} O \mathrm{O}$ and an outer $\mathrm{C}_{3} \mathrm{O}_{4}$ or $\mathrm{Co}_{2} \mathrm{O}_{3}$ in the passive potential region more positive than $\Phi / V$ vs. HESS $=0.75$ in neutral boric acid-sodium borate solution at $p H$ 8.4.

2. A growth model is presented for electrochemical two-layer formation, which explains the observed dependence of film thickness on the potential and on the time of oxidation.

3. The outer layer reaches within $1 \mathrm{hr}$ the stationary thickness which increases nearly linearly with the electrode potential, and the inner $\mathrm{CoO}$ layer requires much longer oxidation time before the stationary thickness is reached. The inner layer thickness that grows in a few hours' oxidation depends not only on the potential but also on the oxidation procedure. It is revealed that the growth of the inner $\mathrm{CoO}$ layer is influenced by the ionic diffusion in the outer layer.

4. Anodic deposition of a $\mathrm{Co}_{3-\Delta} \mathrm{O}_{4}$ layer $(0 \leq \Delta \leq$ 0.33) from $\mathrm{Co}$ (II) ion in solution of $p \mathrm{H} 8.4$ can take place at $\mathrm{Co}$ (II) ion concentrations as small as 1.03 $\mathrm{mg} \mathrm{dm}^{-3}$ in the potential region more positive than $1.2 \mathrm{~V}$. Therefore, the anodic oxide film on cobalt becomes thick in the presence of $\mathrm{Co}$ (II) ion in solution.
5. The ion migration in the anodic oxide film is likely to be assisted by high electric field and represented by the rate equation $i=i_{0} \exp (B \Delta \Phi / L)$ for each individual layer.

6. The self-diftusion coefficient in the inner $\mathrm{CoO}$ layer is estimated to be $D / \mathrm{cm}^{2} \mathrm{sec}^{-1}=6.5 \times 10^{-21}$ $\sim 2.6 \times 10^{-20}$.

\section{Acknowledgment}

One of the authors (T.O.) gratefully acknowledges a scholarship from the Sakkokai Foundation.

Manuscript submitted Aug. 27, 1980; revised manuscript received March 5, 1981.

Any discussion of this paper will appear in a Discussion Section to be published in the June 1982 JouRNAi. All discussions for the June 1982 Discussion Section should be submitted by Feb. 1, 1982.

Publication costs of this article were assisted by Hokkaido University.

\section{REFERENCES}

1. T. Ohtsuka and N. Sato, J. Jpn. Inst. Met., 39, 60 (1975).

2. T. Ohtsuka, K. Kudo, and N. Sato, ibid., 40, 124 (1976).

3. K. Kudo, N. Sato, and T. Ohtsuka, "Passivity of Metals," R. P. Frankenthal and J. Kruger, Editors, p. 918, The Electrochemical Society Softbound Proceedings Series, Princeton, NJ (1978).

4. N. Sato and T. Ohtsuka, This Journal, 125, 1735 (1978).

5. K. Kudo and N. Sato, Bull. Fac. Eng. Hokkaido Univ., No. 61, p. 45 (1971).

6. H. Göhr, Electrochim. Acta, 11, 827 (1966).

7. T. Ohtsuka and N. Sato, Corros. Eng. (Boshoku Gijutsu), 24, 489 (1975).

8. G. J. Yurek, J. P. Hirth, and R. A. Rapp., Oxid. Met., 8,265 (1974)

9. R. D. Shaw and R. Rolls, Corros. Sci., 14, 343 (1974).

10. N. Sato and T. Noda, Electrochim. Acta, 22, 839 (1977).

11. N. Cabrera and N. Mott, Rep. Progr. Phys., 12, 163 (1949).

12. P. Kofstad, "Nonstoichiometry, Diffusion, and Electrical Conductivity in Binary Metal Oxides," p. 100, Wiley-Interscience, New York (1972).

13. R. E. Carter and F. D. Richardson, Trans. AIME, 200, 1244 (1954); 203, 336 (1955).

14. W. K. Chen, N. L. Peterson, and W. T. Reeves, Phys. Rev., 186, 887 (1969). 